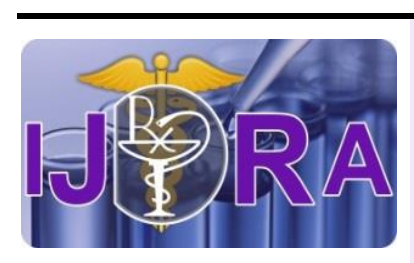

Available online on 15 Jun, 2021 at https://ijdra.com/index.php/journal

International Journal of Drug Regulatory Affairs

Published by Diva Enterprises Pvt. Ltd., New Delhi

Associated with Delhi Pharmaceutical Sciences \& Research University Copyright@ 2013-21 IJDRA

Review Article

Open $\odot$ Access

\title{
Strategic Intellectual Property Management and spin offs during Medical Device Innovation and commercialisation
}

\author{
Suchita Markan* \\ Biotech Consortium India Limited, New Delhi, India
}

\begin{abstract}
Intellectual Property (IP) protection for medical technology innovations is a milestone, generally undermined by Start-ups. Effective and timely IP protection acts as a lifeline for entrepreneurs/start-ups as it not only helps them attract investments and get competitive advantage but also enables marketing tie-ups and potential acquisition by larger companies. This article delineates the strategies for effective IP protection during different phases of technology development to enable medical technology innovators unlock IP potential of their innovations thereby gain competitive edge as well as reap financial rewards. Some interesting case studies and experience sharing by entrepreneurs have also been included for empirical understanding and to serve as practical tools for innovators working in medical device innovation space.
\end{abstract}

Keywords: Innovation, Medical Device, Intellectual Property, Strategy, Commercialisation, Entrepreneurship

Article Info: Received 04 May. 2021; Review Completed 05 Jun. 2021; Accepted 10 Jun. 2021

Cite this article as:

Markan S. Registration Strategic Intellectual Property Management and spin offs during Medical Device Innovation and commercialisation. Int J Drug Reg Affairs [Internet]. 2021 Jun 15 [cited 2021 Jun 15]; 9(2):43-51. Available from: http://ijdra.com/index.php/journal/article/view/469

DOI: $10.22270 /$ ijdra.v9i2.469

*Corresponding author

\section{Introduction}

Technology development pathway for medical devices typically begins with ideation, conceptualisation and proceeds with validation followed by scale-up and product launch. Different forms of IP such as trade secrets, patents, trademarks, industrial designs and copyrights become relevant for evaluation and protection at different stages of the technology development.

The objective of this article is to delineate the strategies for effective IP protection during each phase of the technology development pathway to enable medical device innovators unlock the IP potential of their innovations and reap huge financial rewards. Different real-life case studies of budding medical technology innovators have been included to facilitate better understanding and adoption by innovators.

\section{Case study- NeoBreathe: Value of IP}

"When Windmill Health Technology Pvt. Ltd. set out to build NeoBreathe ${ }^{T M}$ - the world's first foot operated newborn resuscitation device, they were faced with the critical question of how to prevent others from replicating the device? As a Start-up, Windmill Health relied on creating an IP barrier for their invention, says Avijit Bansal, founder of the Company. They undertook patentability assessment of their invention and filed patents to deter rival businesses from using or copying their inventions. However, they soon realised that the actual protection offered by a patent further depends upon financial muscle power, team bandwidth, and onground litigation capability. As part of good IP practices, Windmill Health had set-aside funds and created a dedicated team to keep an IP watch. Also, they understood that patenting their invention was not enough. Competitors could easily come up with ingenious ways of working around the patent. Thus, they went ahead to protect all aspects of their invention through an exhaustive IP strategy including patents, trademarks, industrial design etc. This is known as building an IP wall around your invention. "Since our device is a purely mechanical one, it was critical to build a strong IP fence around it covering various novel aspects of the invention." In addition to protection offered, strong IP also offers as an instrument of transaction by on-boarding partners through sublicensing to amplify the impact of invention. "Building and navigating through a well thought IP strategy, our Company is excelling", says Dr. Bansal."

The journey of medical device innovation through biodesign follows a three "I" process -Identify, Invent and Implement. (1) (Figure 1) 
This " $3 \mathrm{i}$ " process has been referred to in this article to guide the medical device innovators on varied IP aspects linked with each phase. These aspects, their importance and suggested strategies for securing effective IP protection and monetisation have been discussed separately for each phase.

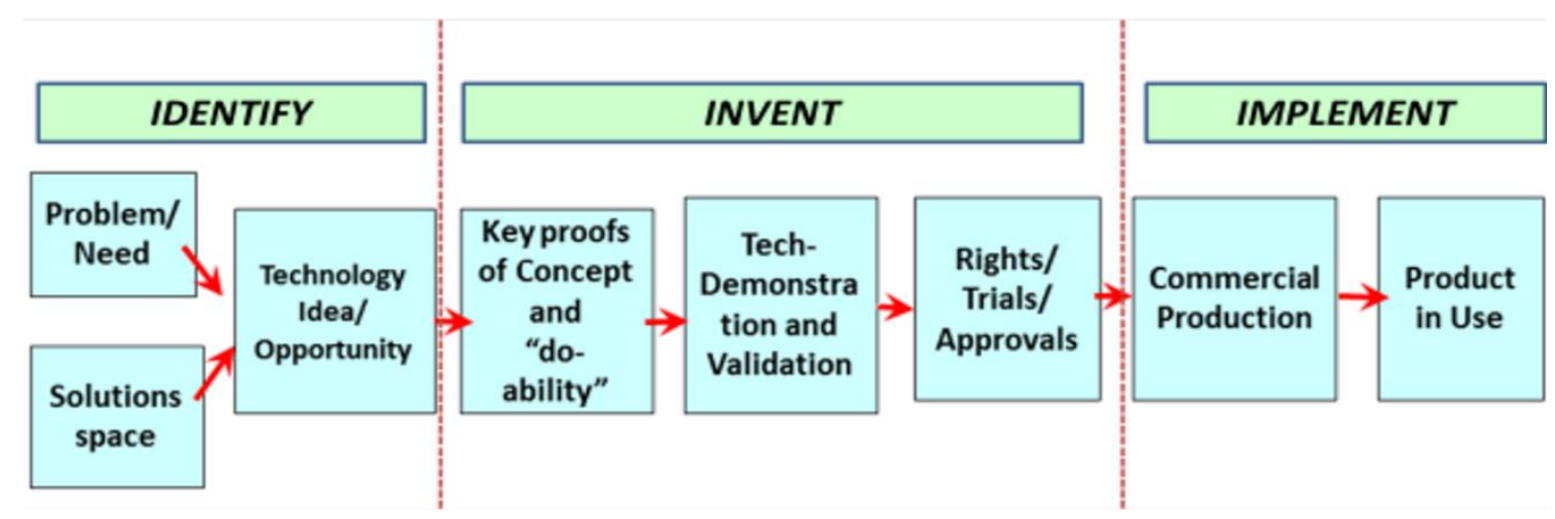

Figure 1. Technology Development Pathway - 3i Process

\section{Data sources/Study selection}

Comprehensive review of literature comprising key documents on IP protection and strategy were studied. More than 100 medical device innovations in India which have been conceptualised and developed as per Stanford Biodesign process were evaluated to select medical device start-up companies with demonstrated experience in effective IP management. Such innovators were then interviewed and requested to share their case studies included in this article.

\section{Summary of Contents}

Phase 1: Identify-Clinical Immersion, needs finding, Understanding Existing Solutions

This step involves immersion in clinical practice to identify unmet healthcare needs based on direct observations at hospitals. Typically, more than 200 needs are identified during this period. These needs are then screened based on market size, patient impact, pathophysiology, competitive landscape, and the opportunity to add value for healthcare stakeholders. Ultimately, needs with the greatest potential for innovation rise to the top of the list for conceptualisation and product development. (1)

To enable the medical device innovator to identify the need with lesser competition and fair scope for innovation, an IP landscape study should be performed. (2) A patent landscape analysis at an early stage shows the white space in the unmet need space, IP trends and helps in preliminary risk identification. (2) Patent landscaping at this stage provides insight into areas which are potentially ripe with existing third-party patents, and also indicate areas that are relatively free and are possibly available for innovation. In addition, researchers may also make use of the landscape to identify groups particularly suited for partnership or collaboration opportunities. (2) By securing patent coverage in a technology space with fewer players, a medical device company can become a dominant player in that space. $(2,3)$
Who owns 'your' IP? This is an important question which needs to be addressed early on during technology development pathway. Usually, inventors at research institute develop and register IP rights created by them in their name before the incorporation of their Company. (4) Any IP created by the inventor(s) prior to incorporation of startup is owned by the founder(s), and not by the startup. In case of research group(s) from one or more institution(s), the IP is either solely or jointly owned by the Institute(s). Such a jointly owned IP is difficult to be licensed for need of approvals from all joint owners. In case of India and Europe, such approvals are required from all the joint owners, while consent from only one joint owner is required in case of IP filed in USA. $(5,6)$ Start-ups inevitably contract out some part of their work to third parties. Even though the Start-up pays for such services, the third party co-owns the IP unless the terms of contract provide otherwise. ${ }^{7}$

It is important to understand that potential investors / acquirers expect the Company to have full and unencumbered ownership control over the IP. $(4,6)$ The IP ownership issues may lead to either collapse of the deal, significant dilution of the valuation, or post deal legal implications. $(4,6)$

It is also important for the innovators to keep the IP developments during research phase as trade-secret, till such time that specific patent applications are filed. Use of Confidentiality Agreements with the staff/employees and consultants, providing limited access to critical information, password protected documents, refraining from publications are some ways to keep the IP as tradesecrets during this period. (7) Figure 2 below shows the IPs relevant for protection in Phase-I.

\section{Phase 2: Invent-Concept Generation, Prototype Development and Creativity}

This phase includes need filtration, concept generation, prototype development etc. It involves generation of multiple concepts for each of the top needs which are further screened based on technical feasibility, IP, regulatory and reimbursement pathways. The 
concepts with the best comparative risk profile are taken

forward into implementation phase. (1)

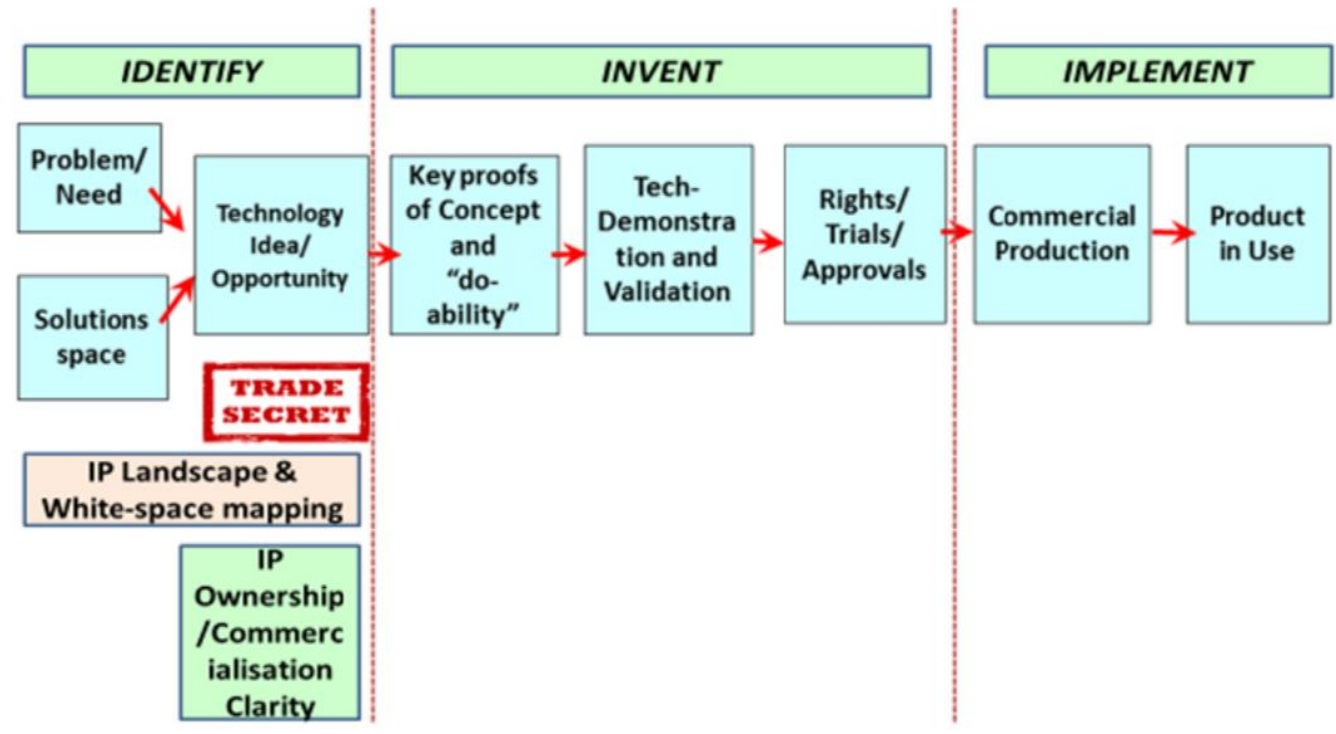

Figure 2. Intellectual Property to be evaluated during Identify Phase

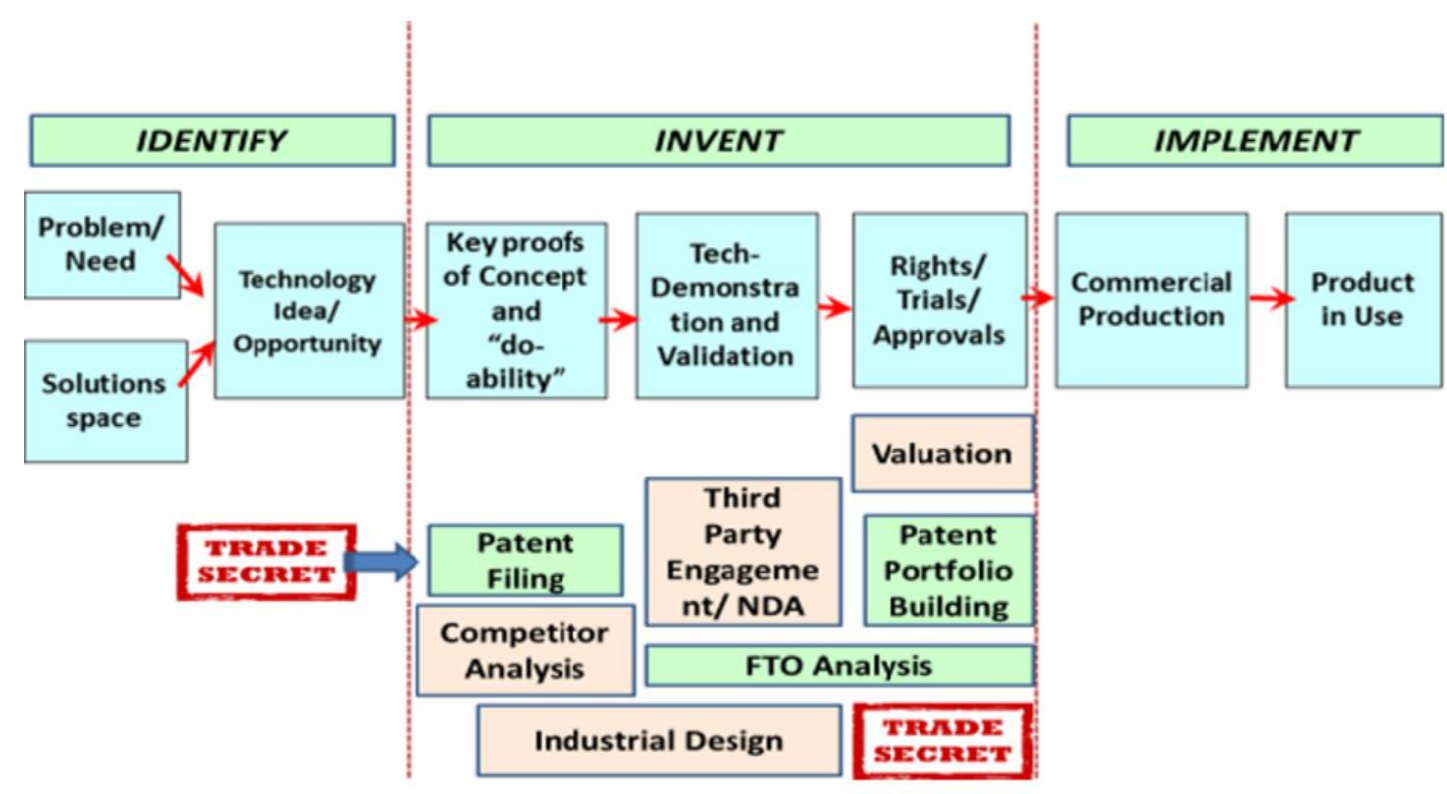

Figure 3. Strategic IP Evaluation and Protection during Invent Phase

The concept, covering the device components and its working mechanism, is generally a patentable subject matter if it qualifies three independent tests of patentability- viz. novelty, inventive step and industrial application. (8) Novelty means that the invention is new and is not available in the public domain. Self-disclosure by the inventor through publications/ presentations etc. before the filing of the patent application often leads to loss of novelty. India and USA Patent law offers provisions of anticipation wherein the applicant has the option to file patent application within one year of disclosure. However, the European patent law requires absolute novelty. Non-obviousness sets the threshold for evaluating whether an invention is new and non-trivial to the extent that it merits patent protection. (9) In order to succeed in showing utility, an invention must have some practical, specific use and industrial applicability. If the invention passes all the three tests of patentability, on examination by the Patent Office, a patent is granted to the applicant. (8)

A patent granted confers upon the patentee the exclusive right to prevent others, from the act of making, using, offering for sale, selling or importing the patented invention. As per Patent Laws, the term of every patent is 20 years from the date of filing of the application. These features of the Patent Law and the criteria for patentability are by and large the same in most countries with few variations in regulations relating to patentability. (8)

There are some exclusions to patentability of medical devices which the innovator should know and strategize for taking patent filing decisions. Medical devices are patentable subject matter in all the key jurisdictions. The method of treatment using the devices is patentable 
subject matter in USA while they are excluded from patentability in India and Europe. (10)

Before proceeding for patent filing for an invention, it is important for an inventor to undertake a detailed PriorArt-search for evaluating novelty of the invention. 'Prior Art' refers to technical information that exists prior to patent filing. This includes an exhaustive search in patent and non-patent literature including publications, conference papers, marketing brochures, products, devices etc. (11)

A prior-art-search prior and patentability assessment before filing a patent ensures the novelty of the invention, enables drafting of suitable claims in view of the prior-art and therefore sometimes speeds up the prosecution process. $(11,12)$ This also helps in strategic planning by the inventor by investing time and funds in an area with no or limited prior-arts. Competitor analysis to evaluate the IP in the competitor products also becomes important at this stage to identify the edge, the innovators technology offers over existing options. Identifying the unique features of the technology before patent filing also helps in filing an appropriately drafted patent. $(12,13)$

As the technology development advances, it is advisable for a company to file other patent applications to effectively protect the new features of the invention. Patent portfolio can also be strategically built to protect the invention in various countries as per business strategy. (14)

Figure 3 shows the relevant forms of IP to be evaluated during Phase-2.

Case study- IndioLabs: Importance of "Building a strategic patent portfolio"
"Indio Labs filed two patents to protect the core technologies underlying their novel device for biopsy. First, the unique dual-function needle geometry, detailing the piercing \& cutting edges, needle angles and the operating parameters were fenced. The second patent covered the procedural safety aspect of injecting the haemostatic agent concurrently for performing a biopsy procedure. These two patents formed the foundation of their novel and innovative soft-tissue biopsy system. Finally, they filed an overarching patent application to protect the device design and more specifically, ingeniously developed mechanisms that enabled the BioScoop needle and BxSeal, haemostatic agent delivery system to perform a safer biopsy procedure for all soft-organs. This comprehensive patent covered the device in totality including device variations that cater to multi-organ applications, key components, method of biopsy and all the other finer aspects.

They aimed to uniquely position themselves in the biopsy market space and not just project a device with their robust patent portfolio. It is one of the key factors that attracted their investors and helped them in negotiating licensing deal(s)."

As patent rights are territorial, the innovator needs to evaluate foreign countries with marketing potential for patent filings. To seek IP protection in foreign jurisdictions, patent application can be filed either through PCT route or conventional route. (15) Filing patents through the PCT route offers a major advantage to the start-ups, by helping them to seek priority for their patent application in 146 countries through a single application and also gives them a time of 30-31 months to undertake market evaluation for selecting countries for national phase filings. (14) (Figure 4)

\section{PCT TIMELINE}

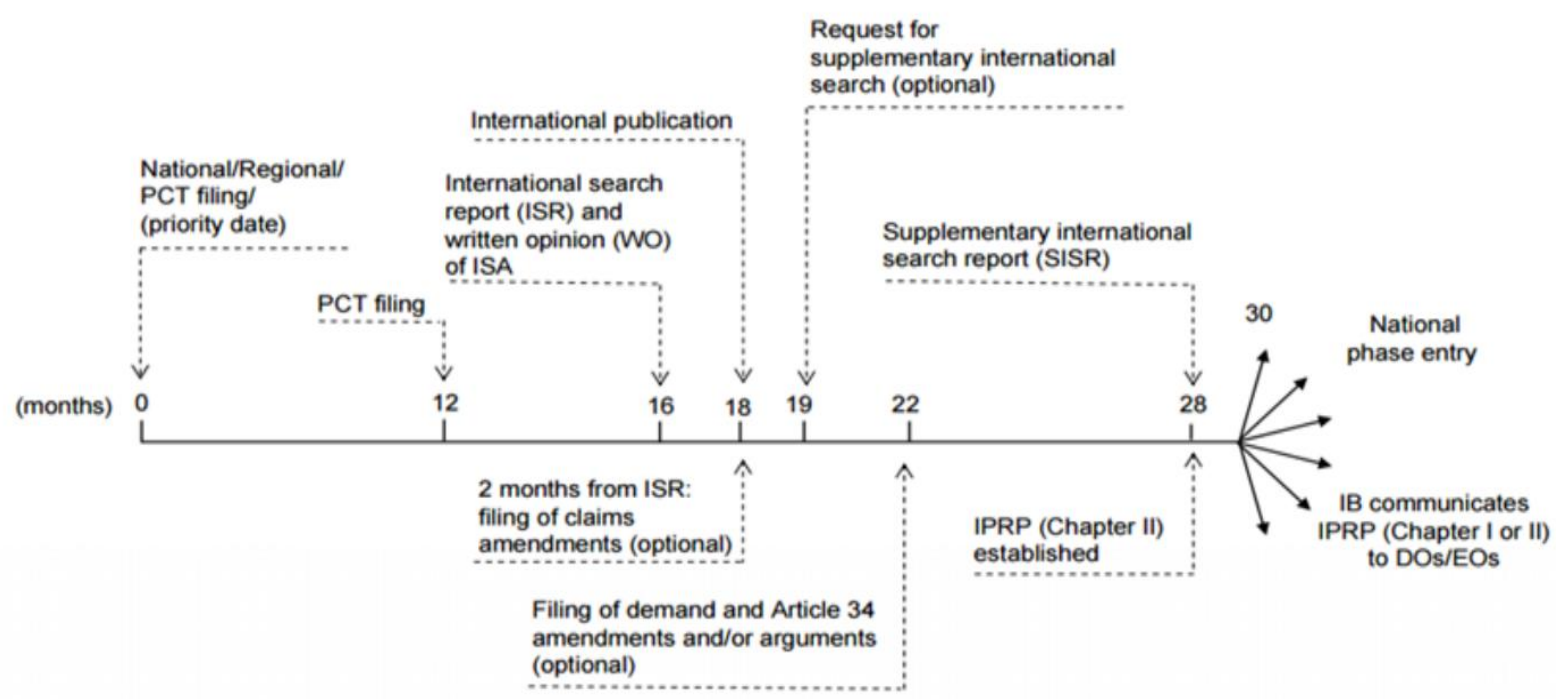

Figure 4. Pictorial representation of the PCT Timeline (16) 
Case study- FlexiCast: Planning a PCT-National Phase Filing Strategy

"Considering the fact that patent filing in different countries require thorough strategizing owing to the costs involved, Pankaj Chhatrala, co-founder, OrthoHeal $^{T M}$, was in dilemma on how to proceed for effective IP protection. Start-up Orthoheal deals with making product FlexiCast which is a breathable, washable and light weight cast for immobilisation of fractured bones. Let's discuss a few factors which helped him take a call:

- Suitability of product in targeted countries: Flexicast offered breathability and washability as major value addition to existing means of casting and splinting. Tropical countries, with high humidity and ambient temperatures came out as natural market choice as normal casts are highly discomforting in such regions. Accordingly, they went ahead to file IP in Brazil and UAE.

- Market size and per capita expenditure on medical treatment: These are very important factors for IP investment decisions by any medtech company. If the total number of addressable patients are not enough, it's difficult to get return on IP investment and market establishment costs. Large market size and willingness to pay for healthcare was a factor that motivated Orthoheal to choose countries including India and USA.

- IP Law enforcement: Orthoheal also considered enforcement of IP law as a deciding factor and picked up countries like Europe, Canada, USA, Australia.

- Market opportunity: In case you are fortunate enough to receive an interest from other countries while in development phase, you must file a patent application in that country. A country level distributor from Vietnam expressed interest to market FlexiCast in Vietnam, Singapore and Malaysia, which was a driving factor for filing Flexicast patent in these countries.

- Technology landscape: While undertaking FTO, Orthoheal found a similar but expired patent in India and USA. Since the patent was not enforceable, they had FTO and opportunity to reap benefits on investments by filing patent in these jurisdictions."

Patent portfolio is an asset valued strongly by the investors. It also opens up new streams of revenue by licensing or assignment of patents to interested companies. It also helps startups to define their competitive edge and emerge as a market leader. $(16,17)$

It is common to see business giants like Google, Facebook Inc, Microsoft corp, Co, Sony corp. etc. participating in patent buying marketplace known as IP3 (Industry Patent Purchase Program) to improve their patent portfolios. Such opportunities can be leveraged by the companies to out-license the patents which are not of their strategic business interest but can potentially provide a parallel revenue stream. (16)

Medical device companies can also consider in-licencing of a technology that is already patented by an academic institution. Licensing such technology(ies) not only helps building a patent portfolio but also de-risks development of a new technology. In-licencing often shortens the time to market for a new technology. (18)

Generally, an innovator team is able to invent a device and develop initial prototypes. However, for taking the device to next level including development of working prototypes and clinical validation, there is always a need to engage external firms. This is the stage where exchange of confidential information with external agencies happen, with need for IP protection through appropriate Agreements such as Confidentiality Agreements, Material Transfer Agreements, Consultancy Agreements etc. depending on the scope of engagement with external firm. (6)

While the innovative content of the invention is protected through patents, the look and feel of the device needs protection through industrial design application. (18) It safeguards copying of the external aesthetic features of the device by competitors and helps in identification of the product by potential customers. (19) The design files of the device are also a creative piece of work which are a subject of copyright protection and if secured properly, could be sold or licensed to companies. (20)

\section{Case Study- Noxeno: Building a Strategic IP Portfolio- Going Beyond Patents}

"A Bengaluru based startup InAccel, led by Dr. Jagdish Chaturvedi, developed a simple nasal foreign body removal device called Noxeno in the year 2012 through DBT supported SIB programme. Nobody could imagine how robust IP protection such a simple and mechanical device would require. This is because a simple but innovative device like NoXeno can be easily replicated in a short period of time by a competitor organization. Therefore, in this case, an Indian patent was filed immediately at the time of early prototyping and a subsequent PCT international filing was carried out to establish priority across the globe as the product was evolving. Importantly, the design was registered and protected early on and the name, logos, trademarks were also secured. As the design of the technology improved, the design registration had to be updated and filed accordingly. In fact, newer IP was generated as the device grew closer to commercialisation and subsequent new filings were undertaken by InAccel. An active and aggressive IP strategy needs to be implemented in order to protect a simple and easy to replicate device is the key lesson for innovators."

Conducting a Freedom to Operate search (FTO) to evaluate the possibility of commercialising a product/ process without infringing on others' patent rights is an important step. FTO search should preferably be carried out at an early stage of product development so that the innovative company does not end up incurring huge development costs for a potentially infringing product 
(21). A FTO search is helpful in many ways including minimizing the risks of infringing upon the patent rights of others, identifying relevant expired patents that may be of use, craft appropriate "inventing around" strategies considering potentially overlapping patents, exploring cross-licensing/ licensing options etc. A FTO search needs to be repeated during the product development cycle, particularly before product launch. (21)

\section{Case Study - Windmill Health, India: Assessing the Freedom to Operate}

"As inventors, it was critical for us to know whether we were infringing upon someone else's patents that might be still operational in India or other target markets. This is where FTO search was important." says Dr. Avijit. Comprehensive FTO searches were conducted by our team and fortunately, the searches revealed wide freedom to operate, as well as significant white space to patent various aspects of our invention. These searches laid a strong foundation for further development of a product as well as IP that later facilitated sub-licensing to a leading global partner. "A critical IP strategy and assessing FTO at each stage of technology development, paid us well in the long run wherein NeoBreathe ${ }^{T M}$ is now being commercially sold in 9 countries including India, Africa etc.," he exuded confidence."

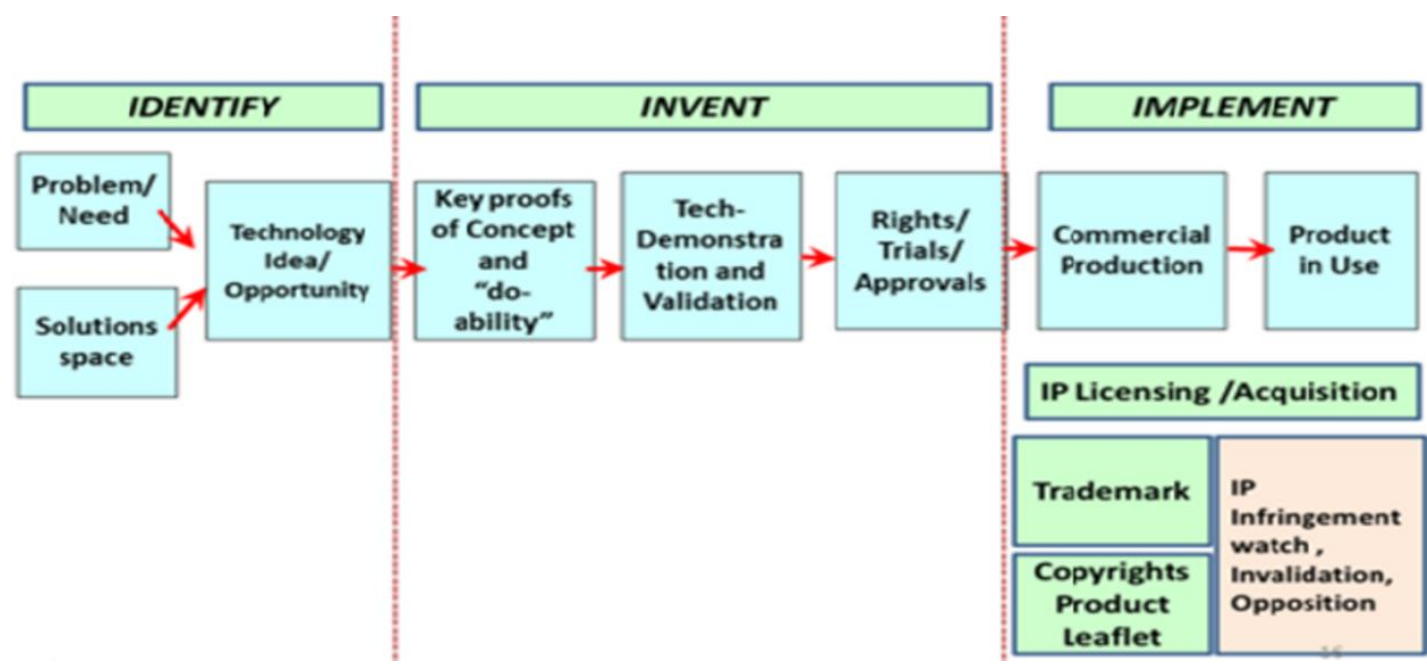

Figure 5. Strategic IP Evaluation and Protection during Implement Phase

\section{Phase 3: Implement- Product Development \& Commercialization Strategy}

This phase comprises prototype refinement in consultation with the clinicians, undertaking clinical validation. A viable business model is then created, which includes understanding sales and distribution, financial modelling, funding strategies i.e. venture capital, corporate funding etc. marketing and stakeholder strategy.

As this phase involves device development for sales, various forms of IP such as trademarks and copyrights become important. The trademark / service mark is adopted by an organization to identify its goods or services and distinguish them from others. Careful identification and filing of a trademark application for the device at this point pays in long run when the device starts selling hugely and gathers brand value. On the other hand, selecting a weak trademark can lead to marketing challenges, unexpected costs and potential litigation. (22)

Businesses quite often select names which describe their goods or services and sometimes incorporate generic or merely descriptive terms. This practice can result in consumer confusion, lost business, and can also lead to loss of a highly valuable monetary asset, i.e. trademark. The use of TM above the wordmark which has been filed and use of $\mathrm{R}$ above the registered trademark, as a suffix prevents infringers from using the trademarked word for their products. (23)
While selecting a wordmark to be used as trademark, it is advised to do a trademark search to evaluate the novelty of the word being chosen as trademark. It is also imperative to register the mark in trademark registry in the jurisdictions which are the potential markets as these are territorial rights. (22)

As per the regulatory requirements, every medical device product should have a product leaflet which describes the product and entails instructions for its use. Such product description is also protected through copyright as a literary work, and the product photo included in the leaflet is protected as an artistic work. If someone else uses the product description and photos without company's consent, the company has a right to sue the infringers. It is important to mark any packaging, instruction leaflets and advertising material with a () notice to deter potential infringers as it is prima facie evidence of ownership. (23)

A detailed FTO search, as a clearance search for planning sales is pertinent before product launch. As the patent rights are territorial, the scope of FTO study should be restricted to countries wherein one plans to commercialise its products. The patent portfolio of competitors in the technology domain can also be evaluated as an additional strategy while undertaking FTO search to get clearance opinion. $(19,21)$

As the claims granted in a patent by the patent office will define the scope of legal implications through FTO, the status of potentially overlapping patents should be 
checked at each national patent office in the countries of interest. If the FTO search at this stage reveals potentially blocking patents, appropriate strategy needs to be adopted by the company including exploring licensing, cross-licensing opportunity etc. Defensive strategies could also be adopted including arguments for non-infringement, invoking invalidation or opposition proceedings to "clear the way" for marketing the invention. $(19,21)$

\section{Case Study- InAccel: Freedom to Operate- A Clearance Search for Planning Sales}

"Dr. Jagdish Chaturvedi, an ENT surgeon and an entrepreneur was involved in the development of a surgical tool based on a well-established technology, but the same could not penetrate the Indian healthcare system well for numerous cost related reasons. In such a situation, in the presence of prior-art, he knew it well that there was no IP to be protected. Though the technology developed by InAccel had novel features, these features were well protected through IP filing by other Medical Device companies. They were in a dilemma whether they could even develop and commercialise this technology in India or not. On consulting a law firm, it was clear that there was no IP to protect, however, they had a Freedom-to-operate in the Indian subcontinent since the predicate company had not filed a patent in the Indian territory. So, they were able to successfully launch and commercialise the technology in India. The team is currently evaluating other territories where they could expand the reach of their technology based on FTO search report."

Appropriate dealing with any IP transaction including licensing, cross-licensing, acquisition, merger, joint venture etc. requires valuation of the IP assets. Valuation of the IPs possessed by company helps them realize the economic value of these assets and thereby assists in realising good deal value on IP transactions. A start-up company generally does not have established market channels or sufficient muscle power to enable market reach-out of its product(s). Such companies generally prefer marketing tie-ups or acquisition by larger companies. In either case, valuation of the IP is imperative to ascertain economic worth. (24)

Companies/licensor(s) use various methodologies for undertaking IP valuation including cost-approach, market approach, Discounted Cash Flow (DCF) method, bench-marking deals etc.

Selecting the valuation method in a given situation is complex and depends upon several factors such as type of IP at stake, level of technology development etc. Medical device companies have witnessed immense growth through valuation and acquisition of IPs. (24) (Figure5)

IP has its role even after product market launch. IP infringement watch, invalidation and oppositions are some of the focus areas in the Implement/ Commercialisation phase. (25)

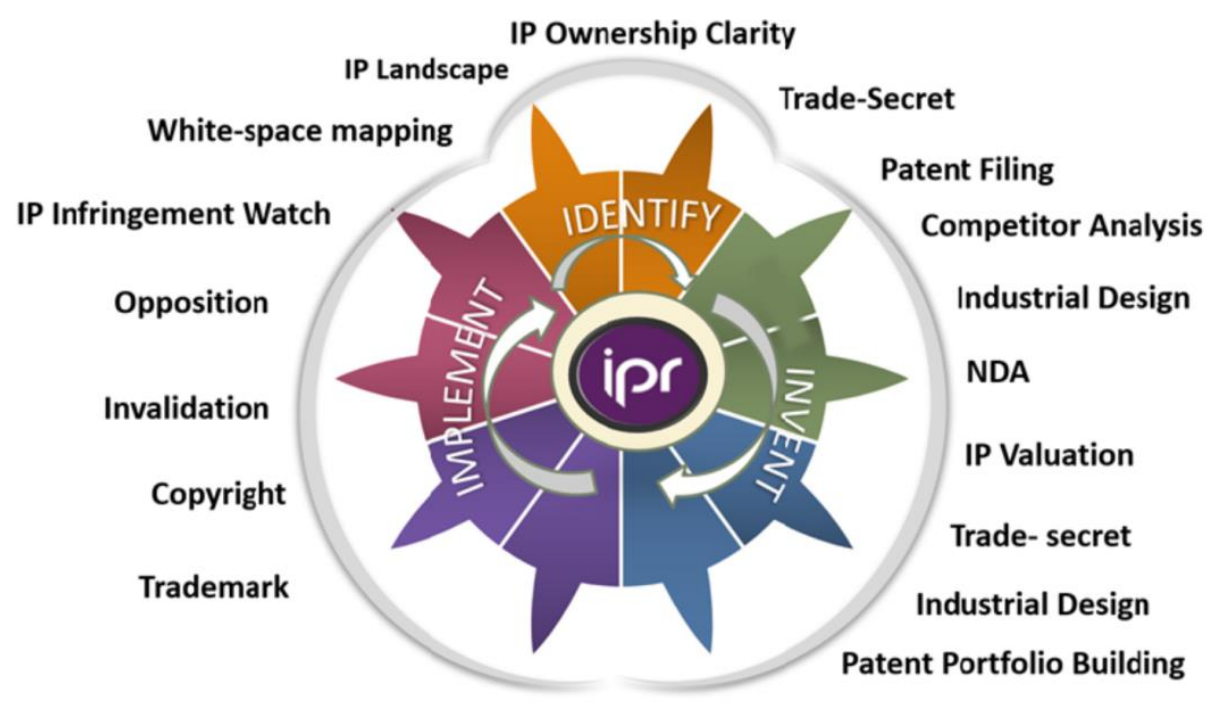

Figure 6. Comprehensive IP Management during Medical Device Technology Development

In the post launch phase, one may find third parties making and selling deceptively similar products. It may prompt one to use offensive strategy (suing the infringing party) or even call for defending suits/actions initiated by a third party. Therefore, holders of IP must foresee such eventualities and create a mechanism to deal with it. During commercialisation phase, oppositions/ revocations of patents by competitors could also be confronted. The competitors may try to invalidate your patent as a strategy to clear their way or buy time for pushing their sales. Appropriate strategies and adequate planning by a company for such IP matters proves to be useful. (25)

\section{Conclusion}

As it is said, forewarned is forearmed. Building IP strategy right in the beginning of the innovation process and implementing it rigorously is crucial for a medical device innovator. It helps in taking risk management decisions in relation to $\mathrm{R} \& \mathrm{D}$, product launch and commercialization. Medical devices encounter special circumstances in the realm of IP. As the market for medical devices grows and becomes far more crowded, getting a commercial edge over your competitors is of even more importance. Strategic IP management is one way to do that. The importance of IP valuation should 
not be underestimated, particularly if one foresees inviting investments or to sell it to a larger corporation. A strategic patent portfolio is crucial to a medical device company's survival and growth and can help secure funding. For early-stage medical device companies, patents are often an important way for investors to place a value on a company's technology and evaluate the potential success of the investment. Licensing an already-tested, patent-protected technology is advantageous and can help early stage companies quickly establish their presence in the technological space.

The medical device startup should spend time for strategically building the patent portfolio with a clear focus on its business objectives, company valuations, potential licensing opportunities, geographic markets, regulatory requirements, patent strength and more importantly; the expenses involved in filing, maintenance and prosecution of the patents. An effective IP strategy including a delicate mix of patents, trademarks, industrial design, trade secrets, copyrights, lay out designs, as may be appropriate should be planned and implemented by the entrepreneurs to build an IP fence around the invention (Figure. 6). Maintaining IP ownership and inventorship sturdiness through appropriate contracts with service providers/consultants is also imperative to ensure commercialisation of the technologies. Different IP strategies including defensive, offensive and back-up strategies should be well thought off by the company for enabling wider market reach-out of the product enabling business success.

\section{Acknowledgements}

The author gratefully acknowledge the contributions of Dr. Avijit Bansal, Founder and CEO, M/s Windmill Health Pvt. Ltd., Delhi, India, Dr. Pankaj Chhatrala, $\mathrm{CEO}$ and Managing Director, M/s JC OrthoHeal Pvt. Ltd., Surat, India, Mr. Siraj Bagwan - Founder and MD, $\mathrm{M} / \mathrm{s}$ IndioLabs Pvt. Ltd, Bangalore, India, Dr. Jagdish Chaturvedi, Founder and CEO of HiiiH Innovations Pvt Ltd \& Director, and former Director Clinical Innovations and Partnerships at Innaccel Acceleration Services Private Limited, Bangalore, India for providing the case studies included in this article. The case studies are based on real-life IP challenges and strategies adopted by the Start-ups for establishing unique IP and business advantage. The Start-up case studies included in this article are from Stanford India Biodesign programme (SIB), which is a Department of Biotechnology, Government of India supported programme being implemented at AIIMS and IIT Delhi, with techno-legal management by BCIL. The author gratefully acknowledges and thank DBT for supporting this programme.

Financial Disclosure statement: The author received no specific funding for this work.

Disclaimer: The information in this article was prepared by me in my personal capacity. The opinions expressed in this article are my own and do not reflect the view of the employer or any association.

\section{Conflict of Interest}

The author declares that there is no conflict of interest regarding the publication of this article.

\section{References}

1. Stefanos Zenios, Josh Makower, Paul Yock, Todd J Brinton, Uday N. Kumar, Lyn Denend, Thomas M. Krummel. Biodesign: The Process of Innovating Medical Technologies [Internet]. Cambridge University Press; 2009 [cited 2021 Apr 02]. Available from:

https://www.gsb.stanford.edu/faculty-

research/books/biodesign-process-innovating-medicaltechnologies

2. Trippe A. World Intellectual Property Organisation (WIPO). 2015 - Guidelines for Preparing Patent Landscape Reports [Internet]. WIPO; 2015 [cited 2021 Apr 05]. Available from:

https://www.wipo.int/edocs/pubdocs/en/wipo_pub_946.pd $\mathrm{f}$

3. European IPR Helpdesk: Fact Sheet Intellectual property considerations for medical devices [Internet]. European Commission; 2015 Sept [cited 2021 Jun 14]. Available from:

https://www.iprhelpdesk.eu/sites/default/files/newsdocum ents/Fact-Sheet-IP-Considerations-for-Medical-

Devices.pdf

4. Seedcamp - Understanding Intellectual Property: Ownership [Internet]. Seedcamp; 2019 [cited 2021 Apr 12]. Available from:

https://seedcamp.com/resources/understandingintellectual-property-ownership/

5. Avoid jointly owned Intellectual Property-Intellectual Property Expert Group (ipeg) [Internet]. Ipeg; $2021 \mathrm{Mar}$ 28 [cited 2021 Apr 14]. Available from:

https://www.ipeg.com/avoid-jointly-owned-intellectualproperty/

6. Lipsitz R. United States: Practical advice for managing IP issues in outsourcing transactions [Internet]. Kramer Levin Naftalis \& Frankel LLP [cited 2021 April 15]. Available from:

http://www.buildingipvalue.com/06US_Can/105_108.htm

7. Nirwan P. Trade secrets: the hidden IP right [Internet]. WIPO; 2017 Dec [cited 2021 Apr 17]. Available from: https://www.wipo.int/wipo_magazine/en/2017/06/article_ 0006.html

8. WIPO Intellectual Property Handbook. Publication No. 489 (E) ISBN 978-92-805-1291-5 WIPO 2004 Second Edition [Internet]. WIPO; 2008 [cited 2021 Apr 28]. Available from:

https://www.wipo.int/edocs/pubdocs/en/intproperty/489/w ipo_pub_489.pdf

9. Pandey $\bar{S}$. Anticipation of Invention by Intepat [Internet]. Intepat; 2016 Dec 02 [cited 2021 May 02]. Available from:

https://www.intepat.com/invention/anticipation-ofinvention/

10. Differences in Patent Eligibility Around the World [Internet]. Morningside Translations Global Solutions; 2018 Sept 06 [cited 2021 May 01]. Available from: https://www.morningtrans.com/differences-in-patenteligibility-around-the-world/

11. Use of Patent Information (Prior Art) for Technology Management, Yumiko Hamano Innovation and Technology Transfer Section, Patent Division, World Intellectual Property Organization (WIPO) 2009 [Internet]. WIPO; 2009 [cited 2021 May 02]. Available from:

https://www.wipo.int/edocs/mdocs/aspac/en/wipo_ip_cm_ 09/wipo_ip_cm_09_topic7_01.pdf

12. Basics of Patent Searching: WIPO Patent Drafting Course for Patent Agents from the ARIPO Member States and 
Observer States Bastiaan Koster [Internet]. WIPO; 2013 [cited 2021 May 01]. Available from:

https://www.wipo.int/edocs/mdocs/africa/en/wipo_pat_hr e_15/wipo_pat_hre_15_e_1.pdf

13. Patentability Searching and Freedom to Operate by Origin IP [Internet]. Originip [cited 2021 May 02]. Available from:

https://www.originip.com/patentability-searchingfreedom-to-operate

14. Dykeman D. J. Building a Strategic Patent Portfolio that Doesn't Break the Bank. Global Life Sciences \& Medical Technology Group, Greenberg Traurig LLP [Internet]. 2018 July 09 [cited 2021 May 01]. Available from: https://www.mpo-mag.com/issues/2018-09-

07/view_columns/building-a-strategic-patent-portfoliothat-doesnt-break-the-bank/

15. PCT FAQs Protecting your Inventions Abroad: Frequently Asked Questions About the Patent Cooperation Treaty (PCT) [Internet]. WIPO; $2020 \mathrm{Apr}$ [cited 2021 May 02]. Available from: http://www.wipo.int/pct/en/faqs/faqs.html

16. Fayerberg R. and Dykeman D. J. Importance of Maintaining A Balanced Patent Portfolio Building a Strategic Patent Portfolio [Internet]. Intepat; 2017 May 26 [cited 2021 May 03]. Available from: https://www.intepat.com/blog/patent/importance-patentportfolio/

17. European IPR Helpdesk: Fact Sheet Intellectual property considerations for medical devices [Internet]. European Commission; 2015 Sept [cited 2021 May 01]. Available from:

https://www.iprhelpdesk.eu/sites/default/files/newsdocum ents/Fact-Sheet-IP-Considerations-for-Medical-

Devices.pdf

18. Newmarker C. Connected medical devices require strategic patents: Here's why [Internet]. Medical Design \& Outsourcing; 2019 Mar 05 [cited 2021 May 02]. Available from:

https://www.medicaldesignandoutsourcing.com/connected -medical-devices-require-strategic-patents-heres-why/

19. WIPO: Industrial Designs [Internet]. WIPO [cited 2021 May 01]. Available from:

https://www.wipo.int/designs/en/

20. Booth C. Freedom to Operate for Medical Devices [Internet]. Astrazeneca IP; 2010 Oct 11 [cited 2021 May 02]. Available from:

https://www.rsc.org/images/CatherineBooth_tcm18192431.pdf

21. IP and Business: Launching a New Product: freedom to operate, WIPO Magazine [Internet]. WIPO; 2005 Sept [cited 2021 May 03]. Available from: https://www.wipo.int/wipo_magazine/en/2005/05/article_ 0006.html

22. Introduction to trademark law \& practice the basic concepts a WIPO training manual Geneva 1993 (Second Edition) [Internet]. WIPO; 1993 Feb [cited 2021 May 02]. Available from:

https://www.wipo.int/edocs/pubdocs/en/wipo_pub_653.pd $\mathrm{f}$

23. A Handbook of Copyright Law, Government of India, Department for Promotion of Industry and Internal Trade, Ministry of Commerce and Industry [Internet]. Copyright Office [cited 2021 May 02]. Available from: http://copyright.gov.in/documents/handbook.html

24. European IPR Helpdesk: Fact Sheet Intellectual Property Valuation [Internet]. European Commission [cited 2021 May 02]. Available from: www.iprhelpdesk.eu
25. WIPO: Enforcement of Intellectual Property Rights [Internet]. WIPO; 2013 [cited 2021 May 03]. Available from: https://www.wipo.int/publications/en/details.jsp?id=357\& plang=EN 